\title{
Vì sao doanh nhân chọn trường đại học để tài trọ’
}

\author{
Minh Thong Trinh \\ University of Strathclyde \\ Email: trinhminhthong@outlook.com
}

Van Anh Nguyen

University of Huddersfield

Email: vananhnguyen2038@gmail.com

\section{Có những lý do cụ thể khiến cho trường đại học thu hút tài trợ từ các doanh nhân hơn so với các tổ chức từ thiện.}

Cách đây chưa đến 2 tháng, tiến sĩ Charles Huang, nhà sáng lập công ty quản lý đầu tư Pasaca Capital Inc, Mỹ, tài trợ 50 triệu bảng cho Đại học Strathclyde, Glasgow, nhằm tri ân GS Stephen Young, cố trưởng khoa Marketing. Đây là khoản tài trợ lớn nhất mà trường đại học này từng nhận được, cũng là một trong những khoản tài trợ lớn nhất cho các trường đại học Anh. Còn cách đây ít ngày, CEO Vietjet Air Nguyễn Thị Phương Thảo đã ký thỏa thuận hợp tác phát triển nghiên cứu, giáo dục, bao gồm việc đầu tư phát triển một trường đại học thuộc hệ thống Viện ĐH Oxford và thành lập quỹ học bổng, tổng giá trị hợp tác 155 triệu bảng Anh. Hai tin trên đều gây xôn xao hệ thống giáo dục đại học Anh.

Tài trợ trong giáo dục là những khoản quyên góp hoặc hỗ trợ cho các trường đại học với mục đích hỗ trợ việc giảng dạy, nghiên cứu và phục vụ cộng đồng của các trường đại học. Thu nhập của các tổ chức giáo dục có thể biến động theo thời gian cùng với sự thay đổi về số lượng sinh viên, các khoản tài trợ và trợ cấp từ chính phủ. Mặc dù các khoản tài trợ có thể bị ảnh hưởng bởi nhiều yếu tố, tuy nhiên với các quy tắc trong việc quản lý tài chính, các trường đại học vẫn có thể có những nguồn tài chính ổn định. Ví dụ, các trường đại học ở Mỹ thường chỉ sử dụng tiền lãi của khoản tài trợ để chi tiêu hàng năm mà không dùng đến số tiền gốc. Sự ổn định này giúp các trường rất nhiều trong việc hoạch định những chiến lược dài hạn.

Ngoài ra, các khoản tài trợ góp phần đa dạng hóa nguồn tài chính của các tổ chức giáo dục. Với chính sách hai cao: học phí cao - hỗ trợ cao, các trường đại học đã tăng đáng kể số lượng học bổng cấp cho sinh viên trong những năm gần đây. Ở Mỹ hoặc Canada, các trường đại học lớn sẽ tự động cấp học bổng và hỗ trợ tài chính cho các sinh viên theo học mà không cần quan tâm đến hoàn cảnh tài chính của sinh viên. Ngoài ra, các khoản tài trợ cũng cho phép các trường đại học cung cấp dịch vụ giáo dục chất lượng cao với mức chi phí thấp nhất có thể. Điều này đặc biệt quan trọng khi các khoản trợ cấp của Nhà nước đối với các trường bị cắt giảm trong những năm gần đây. Nếu không có các khoản tài trợ, các trường sẽ phải cắt giảm các nội dung trong chương trình học, tăng học phí, và phụ thuộc nhiều hơn vào ngân sách.

\section{Bức tranh quyên góp giáo dục ở Anh}


Thuật ngữ "Endowment" (các khoản quyên góp) xuất phát ở Anh vào thế kỷ 15 và được phát triển rộng rãi trong bối cảnh xã hội giáo dục của Mỹ. Theo Cục Thống kê Giáo dục Anh, trong năm học 2019-2020, các trường đại học ở Anh thu về 931 triệu bảng Anh từ các khoản tài trợ. Con số này tăng gần hai lần so với 532 triệu bảng vào năm học 2014-2015. Đáng chú ý, dường như các trường đại học ở Anh đang có những chiến lược hiệu quả để thu hút những khoản tài trợ khi luôn thu hút được nhiều tiền tài trợ hơn theo từng năm học.

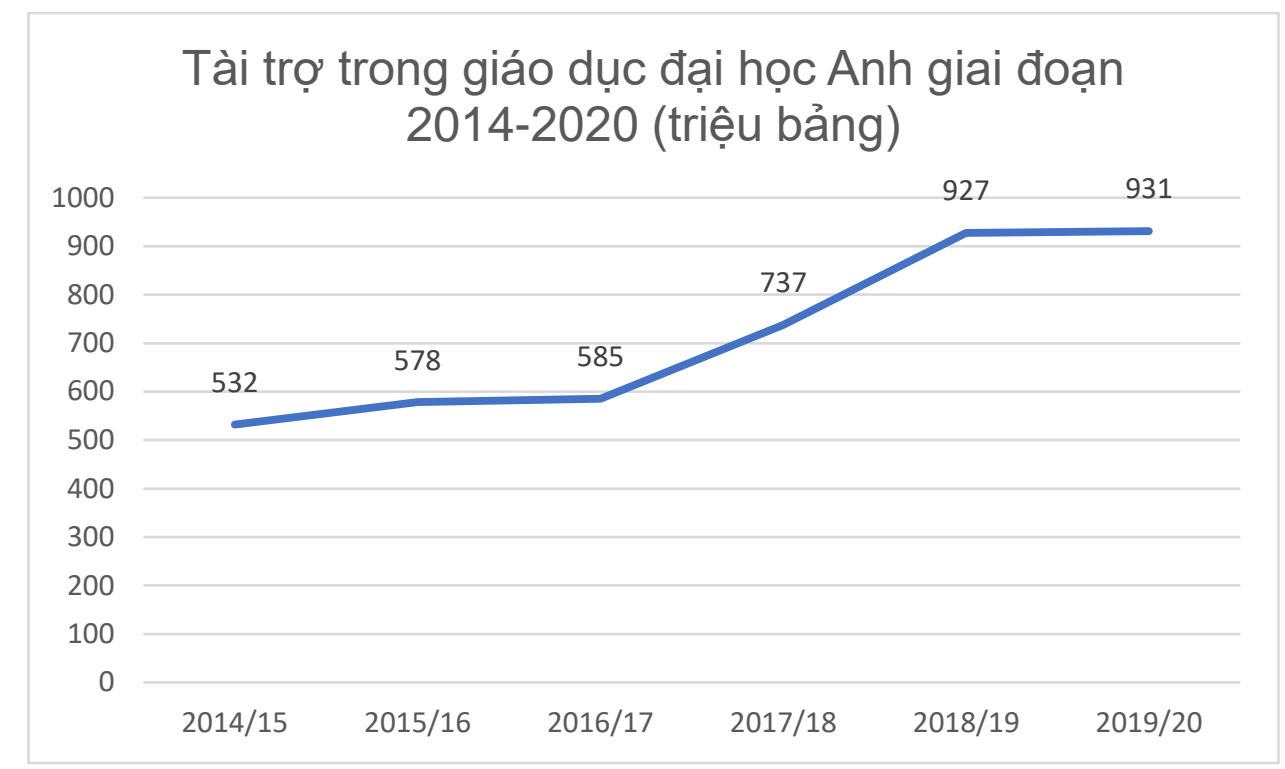

Tài trọ trong giáo dục đại học Anh giai đoạn 2014-2020. Đơn vị tính: Bảng Anh. Nguồn: Cuc Thống kê Giáo dục Anh, 2021

Bên cạnh đó, trong số 10 trường đại học/tổ chức giáo dục tại Anh thu hút được nhiều tiền tài trợ nhất trong năm 2020, có đến 9 trường thuộc Russel Group - nhóm trường hàng đầu tại Anh về chất lượng và danh tiếng. Không có gì ngạc nhiên khi Đại học Oxford với danh tiếng và chất lượng của mình thu về hơn 164 triệu bảng tiền tài trợ trong năm 2020, gần gấp đôi so với Đại học Cambrigde xếp thứ hai với hơn 85 triệu bảng bảng.

\begin{tabular}{|c|c|}
\hline Tên trường & Thu nhập từ các khoản tài trọ' (bảng Anh) \\
\hline University of Oxford & $164,804,000$ \\
\hline University of Cambridge & $85,448,000$ \\
\hline $\begin{array}{c}\text { London School of Economics and Political } \\
\text { Science }\end{array}$ & $58,469,000$ \\
\hline Regents Theological College & $48,269,000$ \\
\hline The University of Edinburgh & $37,821,000$ \\
\hline $\begin{array}{c}\text { Imperial College of Science, Technology and } \\
\text { Medicine }\end{array}$ & $28,264,000$ \\
\hline University College London & $26,576,000$ \\
\hline London Business School & $19,065,000$ \\
\hline King's College London & $16,835,000$ \\
\hline The Prince's Foundation & $15,155,000$ \\
\hline
\end{tabular}


Thu nhập tù các khoản quyên góp của các truờng đại học/tổ chức giáo dục tại Anh trong năm 2020. (đơn vị tính: bảng Anh). Nguồn: The Tab, 2021

Các trường đại học thường khuyến khích sinh viên, cựu sinh viên tham gia tích cực vào các hoạt động đóng góp cho cộng đồng. Thậm chí, một số trường đại học lớn còn đưa tiêu chí này vào tuyển sinh. Trong bối cảnh các chương trình, dự án nghiên cứu và chương trình hỗ trợ sinh viên, đặc biệt là sinh viên thuộc nhóm thu nhập thấp, ngày càng mở rộng, các trường đại học cần những khoản tài trợ để tuyển dụng giảng viên giỏi, áp dụng những công nghệ giáo dục tiên tiến và bắt kịp với sự nở rộ của kiến thức. Về tổng thể, các trường đại học cần thêm các nguồn lực không chỉ để nâng cao chất lượng, khẳng định vị thế mà còn tăng hiệu quả trong các chương trình phục vụ cộng đồng.

Từ góc độ của các doanh nhân, họ có nhiều lĩnh vực để làm từ thiện như y tế, bảo vệ môi trường, bảo tồn động vật quý hiếm... Nhưng theo nghiên cứu của TS Beth Breeze, Giám đốc Trung tâm nghiên cứu Từ thiện, Đại học Kent, Anh, các trường đại học luôn dẫn đần trong các nơi nhận tiền tài trợ từ những doanh nhân thành đạt. Điều này có thể giải thích bởi các lý do sau:

\section{Độ tín nhiệm cao}

Các trường đại học thường có lịch sử lâu đời, quy mô lớn và khả năng quản lý tài chính tốt. Họ thường có kinh nghiệm quản lý tài chính với số tiền lớn, lên đến hàng trăm triệu bảng Anh. Với kinh nghiệm đó, các trường đại học sẽ thu hút tài trợ từ các doanh nhân hơn so với các tổ chức từ thiện.

\section{Thể hiện tham vọng và trách nhiệm}

Giáo dục và nghiên cứu được ví như chìa khóa cho sự phát triển bền vững của nhân loại. Chính vì thế, việc quyên góp cho các trường đại học sẽ thể hiện tham vọng và trách nhiệm của các doanh nhân trong việc đem lại những giá trị cho cộng đồng.

Ngoài ra, không ít những trường hợp doanh nhân thành đạt tài trợ cho trường đại học cũ để thể hiện lòng biết ơn với nơi đã đóng góp một phần vào sự thành công của họ.

\section{Quảng bá thuơng hiệu và mở rộng quan hệ kinh doanh}

Với việc đầu tư một số tiền lớn vào các trường đại học, các doanh nhân có cơ hội quảng bá thương hiệu cá nhân lẫn doanh nghiệp. Ngoài ra, khi trở thành một trong những mạnh thường quân của các trường đại học, họ có cơ hội tiếp xúc và thiết lập mối quan hệ với những cá nhân nổi bật, ban lãnh đạo hay mạng lưới cựu sinh viên thành đạt của nhà trường. Điều này sẽ giúp mở rộng kinh doanh và tăng lợi nhuận trong tương lai cho doanh nghiệp.

Trong bối cảnh hiện nay, việc thu hút các nguồn tài trợ, quyên góp là điều rất phổ biến trong hệ thống giáo dục đại học. Thậm chí, các trường đại học cần phải có những chiến lược nghiêm túc trong việc thu hút những khoản tài trợ này bởi điều này vừa giúp các trường đại học có sự phát triển bền vững, vừa đem lại những lợi ích cho các doanh nhân.

- Bài viết cũng được đăng trên Báo Khoa học \& Phát triển ngày 14/11/2021 


\section{Tài liệu tham khảo}

Breeze, B., 2016. The top five reasons the rich like to donate to universities. [online] Available at: <https://theconversation.com/the-top-five-reasons-the-rich-like-to-donate-to-universities-69434>

Hesa.ac.uk. 2021. What is the income of HE providers? | HESA. [online] Available at: <https://www.hesa.ac.uk/data-and-analysis/finances/income.

The Tab UK. 2021. These are the 25 most well-endowed universities in the country. [online] Available at: <https://thetab.com/uk/2021/07/16/these-are-the-25-most-well-endoweduniversities-in-the-country-215400> 